\title{
Mesoporous Silica from Rice Husk Ash
}

\author{
V.R. Shelke ${ }^{1}$, S.S. Bhagade ${ }^{1 *}$, and S.A. Mandavgane ${ }^{2}$ \\ 1. Department of Chemical Eengineering, Anuradha Engineering College, Chikhli-443201, \\ India \\ 2. . Department of Chemical Eengineering, National Institute of Technology, Nagpur-440010, \\ India
}

Received: 25th April 2010, Revised: 17th June 2010; Accepted: 24th June 2010

\section{Abstract}

Mesoporous silica is used as a raw material in several areas: in preparation of catalysts, in inks, as a concrete hardening accelerator, as a component of detergents and soaps, as a refractory constituent etc. Sodium silicate is produced by reacting rice hull ash (RHA) with aqueous $\mathrm{NaOH}$ and silica is precipitated from the sodium silicate by acidification. In the present work, conversion of about $90 \%$ of silica contained in RHA into sodium silicate was achieved in an open system at temperatures of about $100{ }^{\circ} \mathrm{C}$. The results showed that silica obtained from RHA is mesoporous, has a large surface area and small particle size.

Rice Husk is usually mixed with coal and this mixture is used for firing boilers. The RHA therefore, usually contains carbon particles. Activated carbon embedded on silica has been prepared using the carbon already present in RHA. This carbon shows good adsorption capacity. (C) 2010 BCREC UNDIP. All rights reserved.

Keywords: Sodium silicate; Rice husk ash; Activated Carbon

\section{Introduction}

Globally, approximately 600 million tons of rice paddy is produced each year [1]. On an average $20 \%$ of the rice paddy is husk, giving an annual total production of 120 million tons. This husk is used as fuel to generate process steam. The husk contains about $75 \%$ organic volatile matter and the balance $25 \%$ of the weight of this husk is converted into ash during the firing process. The ash is known as rice husk ash (RHA). Silica in amorphous form is obtained from RHA produced when Rice Husk is burnt in controlled temperatures below $700{ }^{\circ} \mathrm{C}$. The transformation of this amorphous state to crystalline state takes place if the ash is exposed to high temperatures of above $850^{\circ} \mathrm{C}$ [2]. While crystalline silica is used in ceramic [3] and in cement industry [4], amorphous silica has many uses [5]. In India, about 20 million tons of RHA is produced annually [6]. This RHA contains around $85 \%$ - $90 \%$ silica [3].

There are a number of uses for the RHA and silica such as - In the manufacture of refractory bricks $[3,8]$, in water purification treatment $[4,9]$, for vulcanising [5], as insulation powder in steel mills [6], as a source of silicon [6], etc.

To obtain silica, RHA is treated with sodium hydroxide forming sodium silicate. Sodium silicate is then treated with sulphuric acid to precipitate silica. The sodium sulphate formed remains in solution. Crystalisation of sodium sulphate from the aqueous solution is energy intensive and hence uneconomical. Mukunda et al. [7] use carbon dioxide gas for neutralisation generating sodium bi-carbonate and silica. They treat Sodium bi-

* Corresponding Author.

E-mail: uniinfo_ngp@sancharnet.in; Tel.: +91-7264-243274 
carbonate with calcium hydroxide, producing calcium carbonate and caustic soda. The caustic soda is recycled to be used in the digester. The downside of such a process is the disposal of calcium carbonate. Conversion of calcium carbonate to calcium hydroxide for recycle has a large carbon footprint. Nittaya Thuadaij and Apinon Nuntiya [11] obtained nanosilica from RHA by boiling RHA with $\mathrm{NaOH}$ solution for 10 hours.

In the present work, we have treated RHA with aqueous $\mathrm{NaOH}$ for about 1 hour and at low temperatures to convert the silica to sodium silicate. We have used o-phosphoric acid for neutralisation. The precipitated silica is filtered off. The silica produced is mesoporous with a large pore surface area. The filtrate consists of sodium phosphate which can be used in agriculture without further processing. Experiments conducted at a farm have shown improved yields of Chilli crop when the sodium phosphate solution was used as a conditioner. There is no need for any separation operation as the aqueous solution of sodium phosphate can be directly used in the drip irrigation system. This makes the process economically viable.

When carbon is present in appreciable quantities in the RHA, an economically attractive option is production of activated carbon embedded in silica. Stephens [10] describes production of

Table 1. Effect of water content in aqueous solution on the yield of silica

\begin{tabular}{lccc}
\hline \multicolumn{1}{c}{ Parameters } & $\begin{array}{c}\text { Run } \\
\text { No. } \mathbf{~}\end{array}$ & $\begin{array}{c}\text { Run No. } \\
\mathbf{2}\end{array}$ & $\begin{array}{c}\text { Run } \\
\text { No. 3 }\end{array}$ \\
\hline RHA g & 10 & 10 & 10 \\
NaOH g & 12 & 12 & 12 \\
Water ml & 30 & 40 & 60 \\
Temp. ${ }^{\circ}$ C & 99 & 99 & 99 \\
Time min & 60 & 60 & 60 \\
\hline Dry $\mathrm{SiO}_{2}$ g & 5.95 & 8.33 & 6.36 \\
\hline
\end{tabular}

Table 2. Effect of $\mathrm{NaOH}$ concentration on the yield of silica

\begin{tabular}{llllll}
\hline $\begin{array}{l}\text { Parame- } \\
\text { ters }\end{array}$ & $\begin{array}{c}\text { Run } \\
\text { No. 4 }\end{array}$ & $\begin{array}{c}\text { Run } \\
\text { No.5 }\end{array}$ & $\begin{array}{c}\text { Run } \\
\text { No. 6 }\end{array}$ & $\begin{array}{c}\text { Run } \\
\text { No. 7 }\end{array}$ & $\begin{array}{c}\text { Run } \\
\text { No. 8 }\end{array}$ \\
\hline $\mathrm{RHA} \mathrm{g}$ & 10 & 10 & 10 & 10 & 10 \\
$\mathrm{NaOH} \mathrm{g}$ & 10 & 11 & 12 & 13 & 14 \\
Water ml & 50 & 50 & 50 & 50 & 50 \\
Temp. ${ }^{\circ} \mathrm{C}$ & 99 & 99 & 99 & 99 & 99 \\
Time min & 60 & 60 & 60 & 50 & 60 \\
\hline Dry $\mathrm{SiO}_{2} \mathrm{~g}$ & 8.03 & 6.98 & 8.76 & 8.62 & 8.68 \\
\hline
\end{tabular}

activated carbon from RHA. He separated the carbon from the sodium silicate by filtration and then used the carbon after completely removing the silicate solution from carbon. We have been able to obtain good quality activated carbon embedded in silica. Our work shows that carbon is embedded in silica particles when silica is precipitated keeping the carbon suspended in sodium silicate.

\section{Materials and Methods}

\subsection{Raw materials}

Rice Husk Ash was obtained from M/s Yash Agro, Nagpur (India) from their power plant. The rice husk is mixed with coal $(10 \%$ coal, $90 \%$ rice husk) and used to fire their boilers. All reagents for synthesis were commercially available and used as received.

\subsection{Procedures}

A). Amorphous Silica: The initial step is extraction of silica from ash as sodium silicate using aqueous sodium hydroxide. This reaction was carried out in an open stainless steel reactor for about 60 minutes at a temperature of $99{ }^{\circ} \mathrm{C}$ and at atmospheric pressure.

RHA contains mostly amorphous silica which reacts at around $90-100{ }^{\circ} \mathrm{C}$ with $\mathrm{NaOH}$ solution to yield sodium silicate. The RHA also contains some unburnt carbon from the coal as also some ash from the burnt coal. A viscous, transparent, colourless sodium silicate solution is obtained after filtration of the reacted slurry. The residue (on the filer medium) consists of the unburnt carbon and coal ash. In the second step of the process, silica was precipitated from sodium silicate by acidification using orthophosphoric acid. The addition of the acid was done very slowly till a $\mathrm{pH}$ of 6.5 was reached. A precipitate of white silica was obtained.

The silica in aqueous solution of sodium phosphate obtained above was filtered. Purification of this silica for removal of sodium phosphate trapped in the silica mass constituted the third step of the process. For this silica was subjected to successive washings with demineralized water. The washings were added to the bulk of sodium phosphate solution. The wet precipitate was dried in an oven for $24 \mathrm{~h}$ at $110^{\circ} \mathrm{C}$ in the final step of the process.

Temperature of digestion was kept constant at $99{ }^{\circ} \mathrm{C}$. The process parameters which were varied were the quantities of $\mathrm{RHA}, \mathrm{NaOH}$, water and time for digestion. For each run the quantity of 
Table 3. Determination of Optimal time for Digestion

\begin{tabular}{lllll}
\hline $\begin{array}{c}\text { Parame- } \\
\text { ters }\end{array}$ & $\begin{array}{c}\text { Run } \\
\text { No.9 }\end{array}$ & $\begin{array}{c}\text { Run } \\
\text { No. 6 }\end{array}$ & $\begin{array}{c}\text { Run } \\
\text { No. 10 }\end{array}$ & $\begin{array}{c}\text { Run } \\
\text { No. 11 }\end{array}$ \\
\hline RHA g & 10 & 10 & 10 & 10 \\
NaOH g & 12 & 12 & 12 & 12 \\
Water ml & 50 & 50 & 50 & 50 \\
Temp. ${ }^{\circ} \mathrm{C}$ & 99 & 99 & 99 & 99 \\
Time min & 40 & 60 & 90 & 120 \\
\hline Dry $\mathrm{SiO}_{2}$ g & 6.45 & 8.76 & 6.14 & 5.70 \\
\hline
\end{tabular}

Table 4. Effect of RHA concentration on the yield of silica

\begin{tabular}{lllll}
\hline $\begin{array}{l}\text { Parame- } \\
\text { ters }\end{array}$ & $\begin{array}{l}\text { Run } \\
\text { No. 6 }\end{array}$ & $\begin{array}{l}\text { Run } \\
\text { No. 12 }\end{array}$ & $\begin{array}{l}\text { Run } \\
\text { No. 13 }\end{array}$ & $\begin{array}{l}\text { Run } \\
\text { No. 14 }\end{array}$ \\
\hline RHA g & 10 & 11 & 13 & 15 \\
NaOH g & 12 & 12 & 12 & 12 \\
Water ml & 50 & 50 & 50 & 50 \\
Temp. ${ }^{\circ} \mathrm{C}$ & 99 & 99 & 99 & 99 \\
Time min & 60 & 60 & 60 & 60 \\
\hline Dry $\mathrm{SiO}_{2}$ g & 8.76 & 8.25 & 9.60 & 10.75 \\
\hline
\end{tabular}

variable parameters.

1) $\mathrm{NaOH}$ concentration: $12 \mathrm{~g}$ of $\mathrm{NaOH}$ was dissolved in $30 \mathrm{ml}, 40 \mathrm{ml}$ and $50 \mathrm{ml}$ of water keeping all other parameters constant. Experiments were carried out to study the effect of $\mathrm{NaOH}$ concentration on yield of silica (Tables 1 and 2).

2) Reaction Time: The digestion of RHA with aqueous sodium hydroxide was carried out for 40, 60,90 and 120 minutes to study the effect of digestion time on yield of silica (Table 3 ).

3) RHA Concentration: Different weights (10 g, $11 \mathrm{~g}, 12 \mathrm{~g}, 13 \mathrm{~g}, 14 \mathrm{~g}$ ) of RHA were dissolved in a fixed quantity of aqueous $\mathrm{NaOH}$ solution to study the effect of RHA concentration on silica yield (Table 4)

Optimum quantity of silica is obtained with 10 g RHA, $12 \mathrm{~g} \mathrm{NaOH}, 30 \mathrm{ml}$ water and a digestion time of 60 minutes.

B) Activated Carbon: RHA was digested with $\mathrm{NaOH}$ solution. The carbon was not separated as in precipitation of amorphous silica. The whole mass (sodium silicate solution and carbon) was acidified with sulphuric acid while under intense agitation. The black precipitate was separated by filtration, washed with hot water several times and dried. This carbon-silica combine was subjected to SEM and BET analyses.

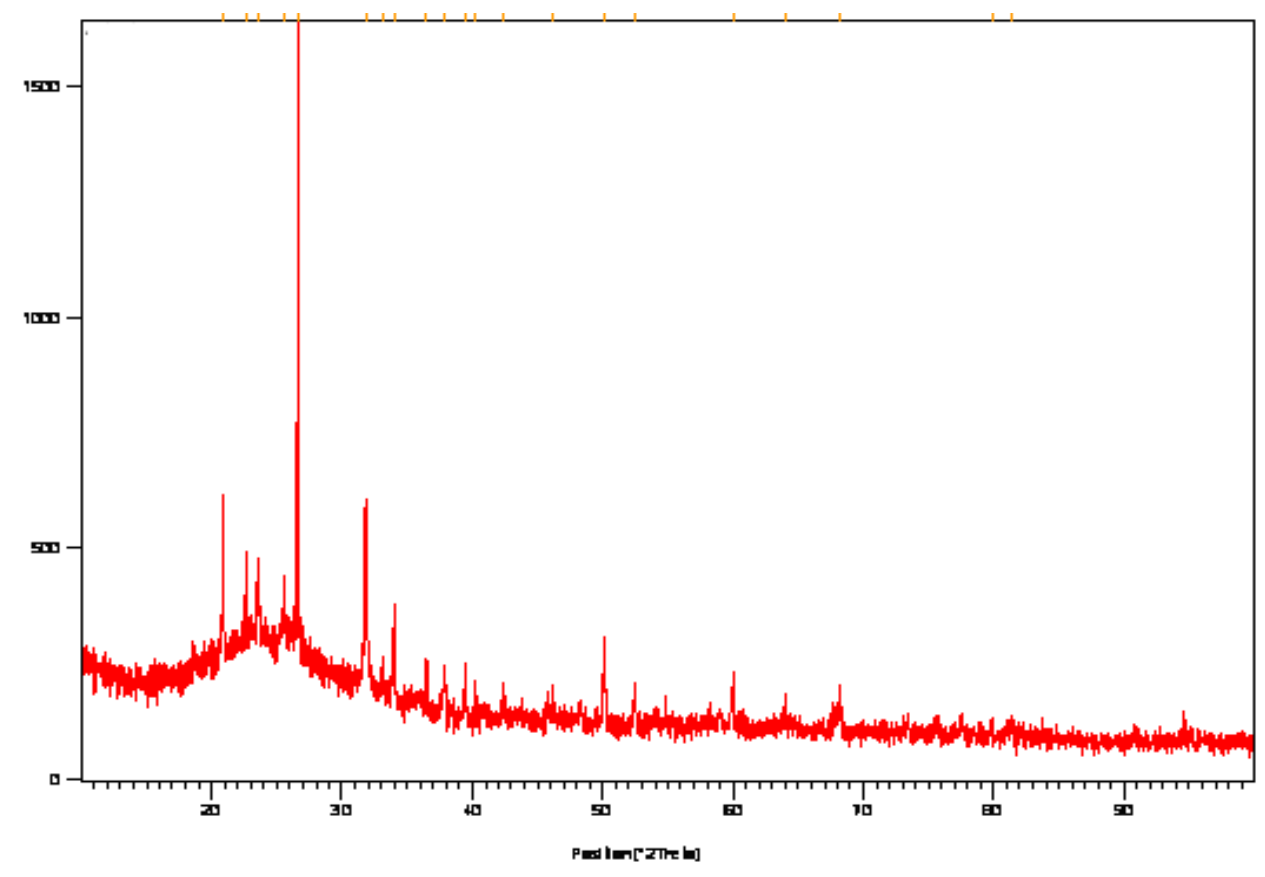

Figure 1. XRD of a typical silica sample 


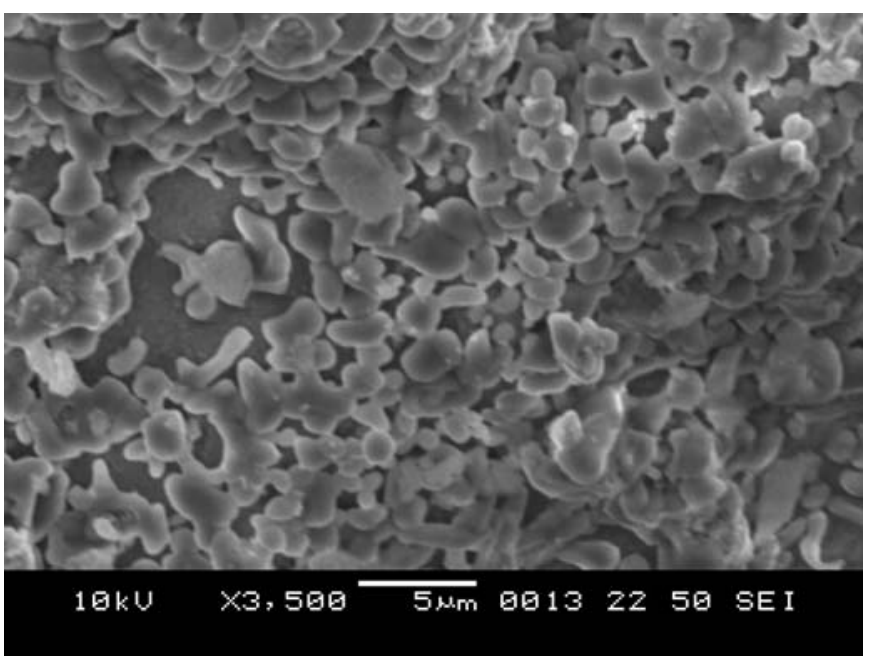

Figure 2. SEM micrograph of a typical silica sample

\subsection{Analytical Instruments}

The instruments used for analysis were for SEM - JEOL Japan (Model No. JXA - 840 A); for XRD - PHILIPS (Expert Pro) and for Pore Size Analysis - MICROMERITICS 9320

\section{Results and Discussion}

The physical properties of the recovered silica are:

- Nature: White amorphous powder

- Purity : $98 \%$

- Bulk density: $1.25 \mathrm{~g} / \mathrm{ml}$

The relevant quantities of the reactants and other parameters are shown in Tables $1-4$.

A) Mesoporous silica: The silica samples obtained were subjected to XRD and SEM analyses. The XRD is shown in Fig. 1 while the SEM micrograph is shown in Fig. 2. It is seen that the silica obtained is largely amorphous with a particle size of about 5 micrometers. BET pore surface area was measured and was found to be $120 \mathrm{~m}^{2} / \mathrm{g}$. The average pore diameter was found to be 19.9317 namometers.

B) Activated Carbon: The SEM micrograph of the activated carbon on silica is shown in Fig. 3. It shows fine particles of silica with a carbon background. The average silica particle size is less than 5 micrometers. The total BET surface area is found to be $100 \mathrm{~m}^{2} / \mathrm{g}$. The average pore diameter was found to be 18.347 namometers .

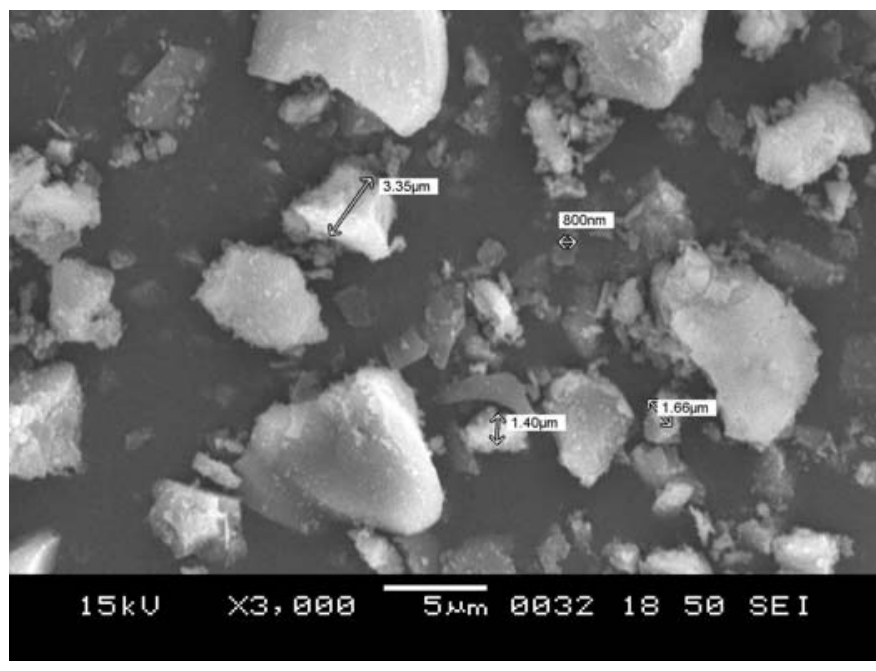

Figure 3. SEM micrograph of Carbon-on-silica

\section{Conclusions}

It is found that it is possible to recover over $90 \%$ of the silica contained in RHA by simple digestion with aqueous sodium hydroxide and precipitation of silica by acidification of the sodium silicate solution so obtained. The silica obtained is very largely amorphous. The XRD shows only traces of quartz (crystalline form of silica). The silica has a small particle size making it suitable for use in rubber and ink industries. The mesoporous structure of silica makes it a potential catalytic (or catalyst support) material.

The black silica with embedded carbon shows a smaller total BET pore surface area of $100 \mathrm{~m}^{2} / \mathrm{g}$ as against that of the white, mesoporous silica of $120 \mathrm{~m}^{2} / \mathrm{g}$. The reduction in surface area may be due to the deposition of carbon in the pores of silica particles.

\section{References}

[1] S. Chandrasekar, K. G. Satyanarayana, P.M. Pramada, P. Raghavan, and T.N. Gupta, (2003), Processing, Properties and Applications of Reactive Silica from Rice Husk - an Overview. Journal of Materials Science, 38, p. 3159-3168

[2] C. Real, M. Alcala, J. Criado, (1996), Preparation of Silica from Rice Husks. Journal of American Ceramic Society. 79, p. 2012-2016. 
[3] C. S. Prasad, K. N. Maiti, and R. Venugopal. (2001). Effect of RHA in White Ware Compositions. Ceramics International, 27, p. 629-635

[4] J. C. Saha, K. Diksit, and M. Bandyopadhyay. (2001). Comparative Studies for Selection of Technologies for Arsenic Removal From Drinking Water. Paper presented at BUET-UNU International Workshop on Technologies for Arsenic Removal from Drinking Water, Bangladesh.UNDP Sustainable Development Networking Program, Technical Session II, May 5th.

[5] S. Siriwandena, H. Ismail, and U. S. Ishakiaku. (2001). A Comparison of White Rice Husk Ash and Silica as Filler in Ethylene-propylene-diene Terpolymer Vulcanizates. Polymer International, 50, p. 707-713

[6] __, (2003). Rice Husk Ash Market. Report, http:.//www.dti.gov.UK/renewables/ Publication/pdfs/exp 129.pdf

[7] H.S. Mukunda, S. Dasappa, P. J. Paul, N. K. S. Rajan, D.N. Subbukrishna. (2003), A Novel Process And Apparatus For The Manufacture Of Precipitated Silica From Rice Husk Ash. Indian Patent No. 216477, 18th Feb, 2003
[8] G.C. Isaia, A.L.G. Gastaldini, and R. Moraes. (2003). Physical and pozzolanic action of mineral additions on mechanical strength of high performance concrete. Cement and Concrete Composites. 25, p. 6976.

[9] E. L. Foletto, M. M. Castoldi, L. H. Oliveira, R.Hoffmann, and S.L. Jahn. (2009). Conversion Of Rice Husk Ash Into Zeolitic Materials. Latin American Applied Research. 39, p. 75-78

[10] D.K. Stefens. (2000). Precipitated silicas, silica gels with and free of deposited carbon from caustic biomass ash solutions and processes. US Patent 6114280

[11] N. Thuadaij, and A. Nuntiya. (2008). Preparation of Nanosilica Powder from Rice HuskAsh by Precipitation Method. Chiang Mai Journal of Science. 35(1), p. 206211 . 